\title{
Addressees' needs influence speakers' early syntactic choices
}

\author{
CALION B. LOCKRIDGE. and SUSAN E. BRENNAN \\ State University of New York, Stony Brook, New York
}

\begin{abstract}
A current debate in psycholinguistics concerns how speakers take addressees' knowledge or needs into account during the packaging of utterances. In retelling stories, speakers are more likely to mention atypical instruments than easily inferrable, typical instruments; in a seminal study, Brown and Dell (1987) suggested that this is not an adjustment to addressees but is simply easiest for speakers. They concluded that manipulating addressees' knowledge did not affect speakers' mention of instruments. However, their addressees were confederates who heard the same stories repeatedly. We had speakers retell stories to naive addressees who either saw or did not see a picture illustrating the main action and instrument. When addressees lacked pictures, speakers were more likely to mention atypical instruments, to mention them early (within the same clause as the action verb), and to mark atypical instruments as indefinite. This suggests that with visual copresence, speakers can take addressees' knowledge into account in early syntactic choices.
\end{abstract}

In spontaneous conversation, speakers appear to tailor their utterances to the needs of their addressees. For example, adult speakers produce short, simplified utterances with exaggerated prosodic contours when speaking to infants (Fernald \& Simon, 1984), and even four-year-olds use simpler language with younger children than they do with adults or with each other (Shatz \& Gelman, 1973). Speakers appear to use gender stereotypes to assess what addressees are likely to know and adjust what they say accordingly (Fussell \& Krauss, 1992). And partners in conversation achieve shared conceptual perspectives, which they mark by reusing the same or closely related referring expressions or syntactic forms (Brennan \& Clark, 1996; see also Garrod \& Anderson, 1987; Levelt \& Kelter, 1982).

That speakers design utterances addressees can understand is not under dispute; what is unclear is exactly when and how addressees' needs impact utterance planning. At one extreme of the debate on audience design is the assumption that a speaker consults a model of the addressee, representing what the speaker takes to be the addressee's current state of knowledge, as well as what they are likely to have as common ground (Clark \& Marshall, 1981). Clark and colleagues provided no predictions about when such knowledge might have its impact; we propose that when relevant, it could be available early in utterance plan-

This material is based on work supported by the National Science Foundation under Grants 0082602, 9980013, and 9711974 and by a W. Burghardt Turner fellowship. We thank Herbert Clark, Victor Ferreira, Nancy Franklin, Richard Gerrig, W. Sid Horton, and Michael Schober for helpful comments. Correspondence concerning this article should be addressed to S. E. Brennan, Department of Psychology, State University of New York, Stony Brook, NY 11794-2500(e-mail: susan. brennan@sunysb.edu). ning, like any other information in memory. Under normal circumstances, such knowledge could be acquired and activated via feedback from an actively participating addressee, ${ }^{1}$ thereby affecting a speaker's subsequent lexical and syntactic choices. Indeed, as speakers refer repeatedly to a particular object, expressions become shorter and more efficient, but only when speakers and addressees can interact (Krauss \& Weinheimer, 1966). People in conversation appear to reach conceptual pacts, or flexible temporary agreements on how to conceptualize objects, and these pacts are more stable with the same partners than with new partners; when speakers change partners, they appear to adapt their conceptualizations (and the referring expressions that mark them) using feedback from their new partners (Brennan \& Clark, 1996). That the forms and meanings of referring expressions are tuned to partners is supported by the finding that people who overhear the conversation (who play no active part in coordinating meanings) do not understand what they hear as consistently as addressees do, even when both kinds of listeners hear the same conversation from the very beginning (Schober \& Clark, 1989).

At the other extreme of the audience design debate are those who have proposed that speakers are egocentric, adjusting utterances to the needs of addressees only when, in a late stage of planning or monitoring, they notice some infelicity (Brown \& Dell, 1987; Dell \& Brown, 1991; Horton \& Keysar, 1996; Keysar, Barr, Balin, \& Brauner, 2000; Keysar, Barr, \& Horton, 1998). After all, people's estimates of another's knowledge are biased toward their own; they tend to overestimate the likelihood that what they know is also known to others (Fussell \& Krauss, 1991; Nickerson, Baddeley, \& Freeman, 1987). The strong form of the view that speakers are egocentric suggests that the first pass at utterance planning may be impervious to so- 
cial context information; early syntactic choices may be made without regard to an addressee's needs (Brown \& Dell, 1987; Ferreira \& Dell, 2000; Horton \& Keysar, 1996).

A nuanced look at audience design was presented by Brown and Dell (Brown \& Dell, 1987; Dell \& Brown, 1991), who distinguished between particular and generic adjustments. Particular adjustments include exaggerated speech to infants and speaking up to distant addressees, as well as adjustments made by experts to novices (Isaacs \& Clark, 1987), native speakers to nonnatives (Bortfeld \& Brennan, 1997), speakers with high spatial ability to ones with low ability (Schober, 1998), speakers who can monitor an addressee's progress in a task versus ones who cannot (Brennan, 1990), or speakers with different conversational goals than addressees (Russell \& Schober, 1999; Wilkes-Gibbs, 1986). Generic adjustments, on the other hand, are those that make speech easier to understand by the average listener (Brown \& Dell, 1987). These include articulatory choices such as pronouncing unpredictable words more clearly than predictable words (Lieberman, 1963) or shortening words that are "given" or inferrable in dialogue, as opposed to "new" (Bard et al., 2000; Fowler \& Housum, 1987; Samuel \& Troicki, 1998). Generic adjustments could also include lexical choices, such as speakers' tendencies to use common, available words that happen to be easy for listeners to process. Brown and Dell pointed out that although generic adjustments could be made through consulting a generic model of the addressee, it is likely that they simply emerge due to parallelism between the production and comprehension systems (such as a shared lexicon and procedures for accessing it). So, strictly speaking, these would not really be "adjustments" at all; speakers say things that are easy for addressees to understand when such things are easy to say.

Speakers have many options for packaging information into utterances. Information that is available or salient early in planning is more likely to find its way into an early clause in an utterance (e.g., Bock, 1986; Levelt, 1989), whereas information easily inferred is likely not to be mentioned at all. When a macroproposition is selected to express an intended concept (e.g., stab) and the concept to be expressed departs significantly from a prototype (e.g., by involving icepick rather than knife), the macroproposition is likely to be tagged with this difference, and icepick will then be mentioned early, in the same clause as the main verb stab (Brown \& Dell, 1987). This sort of packaging is not only natural for speakers but, presumably, benefits addressees when the atypical instrument constitutes news. But it would not count as audience design unless it were most likely when speakers knew that addressees lacked this information.

Brown and Dell (1987; Dell \& Brown, 1991) tested how addressees' needs affect utterance planning by having speakers read stories silently and then retell them to confederate addressees. Their stories included target actions accomplished with either typical or atypical instruments; critically, the stories were illustrated by pictures that speakers knew addressees either could or could not see. Speakers mentioned atypical instruments more often overall and more often early (within the same syntactic clause as the target verb) than they did typical instruments. However, whether addressees could see the pictures was irrelevant. The only reliable effect that might represent a coarse sort of audience design was that speakers mentioned both kinds of instruments in separate clauses after the verb more often when the confederate addressees could not see pictures than when they could. Brown and Dell concluded that speakers' beliefs about the addressees' knowledge did not affect utterance design early in utterance planning, but only relatively late, as a repair. Another program of research drawing similar conclusions has also used confederates as addressees (Horton \& Keysar, 1996; Keysar et al., 2000; see also Keysar \& Horton, 1998; Polichak \& Gerrig, 1998).

Here, we raise the issue of whether it may be difficult or impossible for a confederate addressee to provide the same sort of feedback as a naive addressee; ordinarily, addressees are not informed again and again of the same information by speaker after speaker. The degree to which naive addressees are engaged by a story (as opposed to doing a distracting secondary task) has been shown to affect the feedback they provide and, consequently, the details storytellers present (Bavelas, Coates, \& Johnson, 2000; Pasupathi, Stallworth, \& Murdoch, 1998). Moreover, Brown and Dell's (1987) experiment simulated physical copresence by giving speakers and addressees separate displays, rather than allowing them to easily make eye contact and monitor each other's attention to the same display.

We acknowledge that speakers can adjust to the needs of their addressees by monitoring and repairing utterances (Horton \& Keysar, 1996) and that many features that make an utterance easy to understand emerge serendipitously when speakers' and addressees' needs coincide (Brown \& Dell, 1987). But in contrast to the stronger claims made by these authors that initial utterance planning may be encapsulated with respect to information about addressees' needs (and used only relatively late), we predicted that under normal circumstances (i.e., when addressees are not confederates and actually have needs), speakers may adapt syntactic choices early in utterance production. We used Brown and Dell's storytelling task and the typical/ atypical instrument mention measure to test this prediction with naive addressees who were either fully copresent to the same pictures as the speaker, copresent to separate copies, or lacking pictures altogether.

\section{METHOD}

\section{Participants}

Thirty-seven undergraduates from SUNY at Stony Brook participated in a sentence completion task in order to norm instruments for typicality. Another 144 undergraduates did the storytelling task in 72 pairs. Strangers were paired on the basis of availability and were randomly assigned the role of either storyteller or audience. All were native speakers of English and received either research participation credit or a $\$ 6$ honorarium. 


\section{Design}

Typicality of instruments was varied for each story; each pair saw half the stories in a typical instrument version and half in an atypical instrument version. The stories were randomized to two lists, half with typical and half with atypical instruments. Stories with typical instruments in one list appeared with atypical instruments in the other, and vice versa.

Each pair participated in one of three copresence conditions.

No visual copresence. This condition approximated the situation in Brown and Dell (1987) where partners were separated by an easel that limited visual contact and the storyteller had the only copy of a picture illustrating the story. However, in our experiment, the audience was a naive participant, whereas in Brown and Dell's, this role was played by one of two confederates (who presumably heard each story 40 times).

Separate display copresence. Partners were seated exactly as in the no visual copresence condition, except that the audience saw a copy of the picture identical to the storyteller's while hearing the story.

Full copresence. The storyteller and the audience had full visual contact and sat close together at a right angle, with the easel located at arm's length in front of them. During the story retelling, the easel held a single copy of the picture directly in front of both partners, so each could tell when the other was gesturing or looking at the picture.

\section{Materials}

Norming. Twenty-eight stories were normed, using a sentence completion task. Twenty were taken from Brown and Dell (1987), and eight were written by the first author. The first sentence of each story contained a critical action, and the second sentence contained a blank associated with the instrument used to accomplish the actionfor example,

Adolph hid behind the door and when the man entered the kitchen he stabbed him in the back. He wiped the blood off the rummaged through the drawers.

The stories were given to 37 students, who were instructed to fill in the blank with the first appropriate object that came to mind. The frequency of an instrument's mention was used to estimate its typicality. We selected the 20 stories that resulted in one extremely typical instrument and at least one atypical (but still plausible) instrument. For instance, for the action stab, knife was mentioned over half of the time, and icepick was mentioned once.

Stimuli. The text of each story was provided on an index card. A line drawing showing the instrument was produced for each story version (some were adapted from Brown and Dell's, 1987, illustrations). For the no visual copresence and full copresence conditions, one copy of each picture was needed. For separate display, there was one copy for each partner. Figure 1 contains a sample story/picture set.

\section{Procedure}

Storytelling task. The participants were informed that the storyteller would retell very short stories from memory as clearly as possible to the audience, who would be tested about the stories at the end of the experiment. For each story, the storyteller was instructed to turn over a story card along with its picture and to read the story silently to himself or herself. When he or she was ready to retell the story, he or she was to put the card away and place the picture on the easel where both could see it (full copresence), give the duplicate picture to his or her partner (separate display), or keep the single picture in front of himself or herself on the easel (no visual copresence). The audience was told that he or she could talk freely with the storyteller. Each storytelling session was audiotaped and videotaped. ${ }^{2}$

Recall task. After the storytelling task, the audience completed a recall questionnaire about the stories' instruments (e.g., Adolph stabbed the man with ). This was done not only to mo- tivate both participants with a communicative goal during the storytelling task, but also as an indirect measure of how successfully instruments were communicated.

\section{Analysis}

Transcribing. Both partners' utterances were transcribed. When the action verb and the instrument were mentioned, the transcript included all the speech up to that point. When the action verb or the instrument was not mentioned, the stories were transcribed in their entirety.

Coding. We used Brown and Dell's (1987) coding scheme to categorize the first mention of the instrument in each retold story (see Table 1). The first five categories included explicit mention of the instrument used for the target action. In the first three, the instrument was mentioned in the same clause as the action; these categories are of particular interest because the instrument was available in the speech plan early enough to be packaged with the target action. Categories 4 and 5 also involved explicit mention of the instrument, but in a separate clause after the action. If the speakers mentioned an instrument more than once, only the first mention was coded.

Due to the variability of the speakers' retellings, we permitted several synonyms for the target action in lieu of the verbatim verbs from the stories (but not in lieu of the instrument). Four of the stories could not be coded because, in the retellings, the instruments were mentioned by virtually none of the speakers, who found alternative ways to lexicalize the information in the stories; this left a total of 16 codable stories. The two authors each did the coding independently (with the second author blind to conditions), with agreement $85 \%$ of the time. Any disagreements were discussed until agreement was reached.

The references to instruments were also coded for definiteness. A research assistant (blind to conditions and hypotheses) read each transcript and noted the first referring expression (with article) for the instrument in each story. Then each instrument mention was coded as either indefinite or definite. Mentions were coded as neither if the instrument was combined with the main verb (e.g., knifed) or not marked for definiteness.

Analyses. Analyses were $2 \times 3$ analyses of variance (ANOVAs) with typicality and copresence as fixed factors and pairs of participants as the random factor. ${ }^{3}$ For each ANOVA, two planned contrasts tested for the interaction of typicality with visual copresence (no visual copresence vs. both separate display and full copresence considered together), as well as for the interaction of typicality with the type of visual copresence (separate display vs. full copresence).

\section{RESULTS}

Table 2 summarizes the frequencies with which speakers mentioned atypical and typical instruments in the three copresence conditions. Consistent with Brown and Dell (1987), atypical instruments were explicitly mentioned in connection with the target action more often than were typical instruments $[F(1,69)=8.28, p=.005]$. However, unlike in Brown and Dell's experiment, the pattern of results showed that the forms of utterances did take addressees' knowledge into account, as follows.

\section{Explicit Mention}

When instruments were atypical and addressees lacked pictures, speakers were more likely to mention the instruments (first five categories, Tables 1 and 2) than when instruments were typical or when addressees had pictures $[t(69)=2.12, p<.05]$. 


\section{Typical Version}

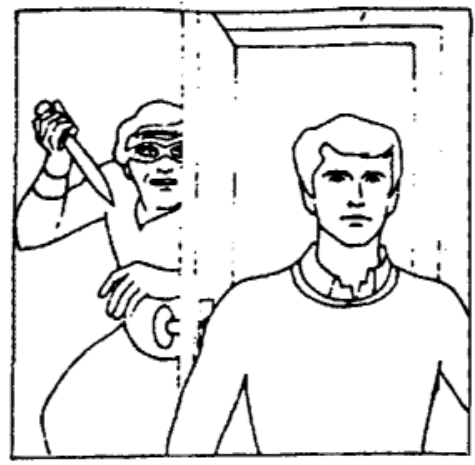

Adolph hid behind the door and when the man entered the kitchen he stabbed him in the back. He wiped the blood off the knife and rummaged through the drawers. Later police investigators found his fingerprints all over the knife and had no trouble catching him.

\section{Atypical Version}

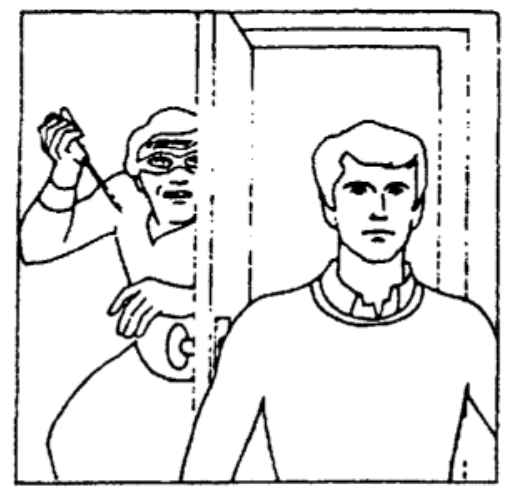

Adolph hid behind the door and when the man entered the kitchen he stabbed him in the back. He wiped the blood off the icepick and rummaged through the drawers. Later police investigators found his fingerprints all over the icepick and had no trouble catching him.

Figure 1. An example of story versions with corresponding pictures.

\section{Within-Clause Mention and Copresence}

Not only did speakers appear to take addressees' needs into account, but they did so by packaging them in the main clause of the target action, rather than as an afterthought or a repair. When addressees lacked pictures, speakers were nearly $15 \%$ more likely to mention atypical than typical objects within the same clause as the target action, as compared with no more likely in the two conditions in which the addressees had pictures [planned comparison of the interaction, $t(69)=2.07, p<.05$; see Figure 2].

In Brown and Dell's (1987) experiment, speakers mentioned instruments in separate clauses after the verb more often when addressees did not have pictures than when they did. This was their only reliable addressee knowledge effect, supporting their conclusion that audience design takes place late, as a repair. Our data showed no reliable difference between no-picture and picture conditions for mentioning instruments in separate clauses after the verb.

\section{Definiteness}

When a speaker mentions an instrument with an indefinite article (e.g., a knife), this marks it explicitly as not yet mutually known (Clark \& Marshall, 1981). Speakers were more likely to mark atypical instruments as indefinite when addressees lacked pictures than when they had pictures but were equally likely to mark typical instruments as definite across all three copresence conditions [planned comparison of the interaction, $t(69)=2.05, p<.05$; see Table 3]. Overall, speakers were more likely to use definite articles with typical than with atypical instruments $[F(1,69)=$ $11.69, p=.001]$. This is consistent with the expectation that typical instruments constituted given information or, possibly, common ground in the context of the actions.

When both partners saw a picture, the type of visual copresence did not matter for any measures (explicit mention, within-clause mention, or definite reference); that is, regardless of whether the addressees viewed the same pic- 
Table 1

Coding Scheme and Examples

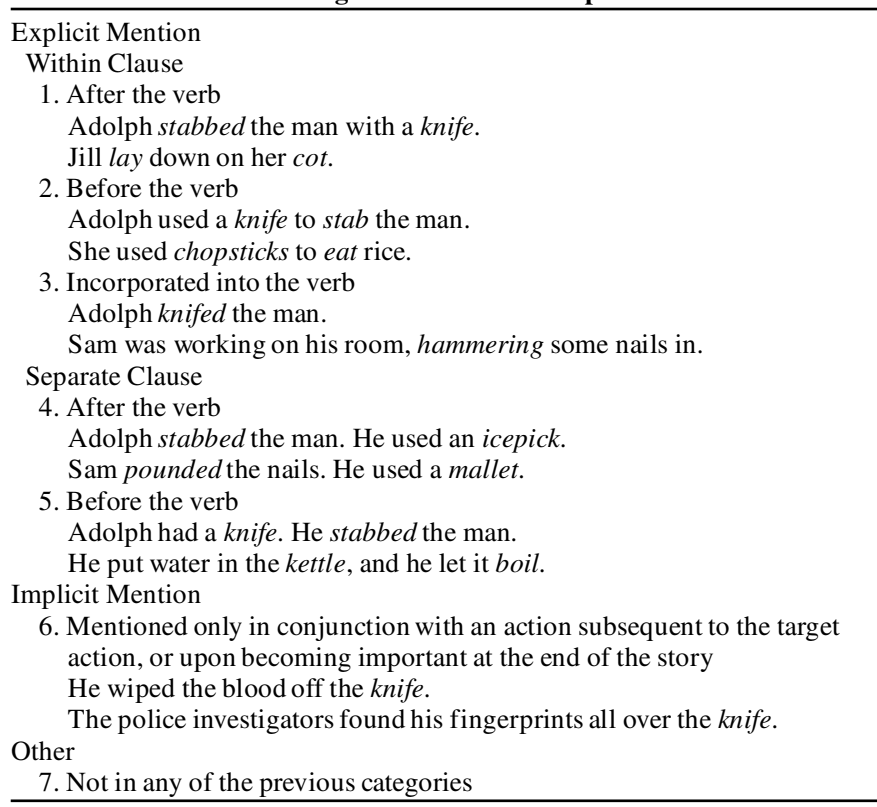

ture as the speaker or a copy, there were no main effects or interactions with typicality.

\section{Communicative Success}

We estimated communicative success by how well audience partners could recall the instruments after the storytellers had finished retelling all the stories. Even though storytellers mentioned more atypical than typical instruments, audience partners correctly produced more typical than atypical instruments on the recall test $[88 \%$ to $74 \%$; $F(1,69)=29.19, p<.001]$. This suggests that the audience partners who were not informed of an instrument by the storyteller inferred it from the target action alone (when the instrument was typical) or understood it from the picture. For typical instruments, the copresence condition did not matter; audience partners were equally accurate with pictures $(89 \%)$ or without $(85 \%)$, whereas for atypical instruments, accuracy was marginally higher with pictures than without [78\% to $65 \%$; planned comparison of the interaction, $t(65)=1.71, p<.10$ ]. Note that for stories with atypical instruments, storytellers slipped up and mentioned either the wrong instrument or no instruments at all $8 \%$ of the time when the audience had no picture, $9 \%$ with duplicate pictures, and $13 \%$ with a shared picture. In these particular cases, the partners with pictures got $45 \%$ of the atypical instruments correct despite storytellers' mistakes, and those without pictures got none correct.

Table 2

Percentages of Explicit Mention for Typical and Atypical Instruments for Each Copresence Condition

\begin{tabular}{|c|c|c|c|c|c|c|}
\hline \multirow[b]{2}{*}{ Category } & \multicolumn{2}{|c|}{ No Visual Copresence } & \multicolumn{2}{|c|}{ Separate Display Copresence } & \multicolumn{2}{|c|}{ Full Copresence } \\
\hline & Typical & Atypical & Typical & Atypical & Typical & Atypical \\
\hline \multicolumn{7}{|l|}{ Explicit mention } \\
\hline \multicolumn{7}{|l|}{ Within clause } \\
\hline After the verb & 30.73 & 41.88 & 31.05 & 32.81 & 29.69 & 30.37 \\
\hline Before the verb & 2.08 & 5.76 & 2.11 & 3.13 & 3.65 & 6.28 \\
\hline Incorporated & 1.04 & 1.05 & 3.16 & 2.08 & 2.08 & 1.05 \\
\hline Total & 33.85 & 48.69 & 36.32 & 38.02 & 35.42 & 37.70 \\
\hline \multicolumn{7}{|l|}{ Separate clause } \\
\hline After the verb & 2.60 & 2.09 & 3.16 & 2.60 & 1.56 & 3.14 \\
\hline Before the verb & 3.13 & 5.24 & 3.68 & 5.73 & 3.13 & 3.66 \\
\hline Total, explicit mention & 39.58 & 56.02 & 43.16 & 46.35 & 40.10 & 44.50 \\
\hline Implicit mention & 52.08 & 35.08 & 50.00 & 41.15 & 49.48 & 41.36 \\
\hline Other & 8.34 & 8.90 & 6.84 & 12.50 & 10.42 & 14.14 \\
\hline Total & 100.00 & 100.00 & 100.00 & 100.00 & 100.00 & 100.00 \\
\hline
\end{tabular}




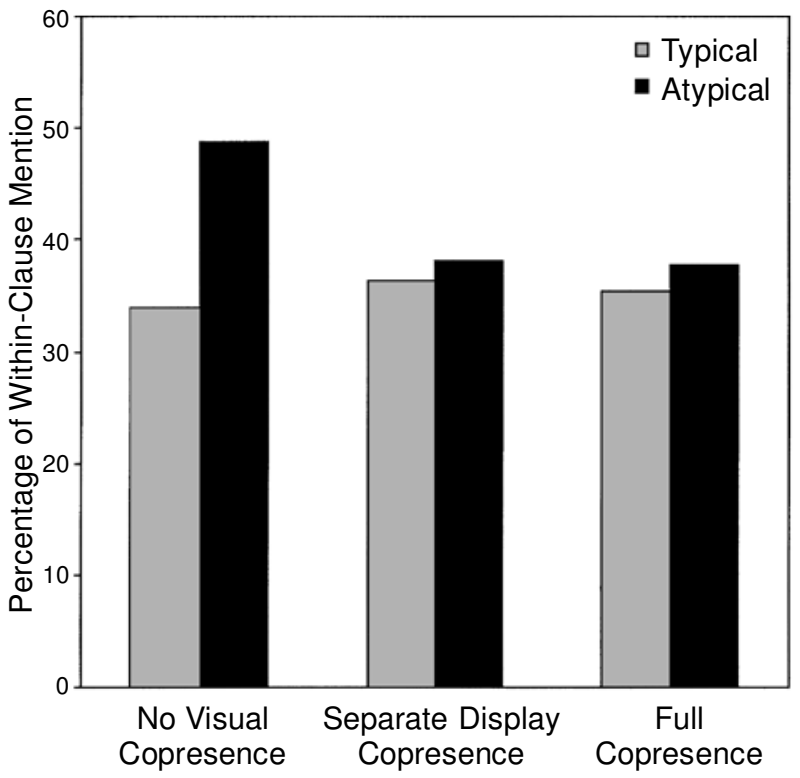

Figure 2. Within-clause mention for typical and atypical instruments in the three visual copresence conditions.

\section{DISCUSSION}

The speakers mentioned atypical instruments more often than typical ones, a generic-listener "adjustment" consistent with what was easiest for the speakers themselves; however, contrary to Brown and Dell's (1987) findings, they also made nonegocentric adjustments to the particular needs of their partners. The speakers were most likely to package instruments early in utterances when the addressees lacked pictures and when the instruments were not inferable from the story's context. In converging evidence, instruments were most often marked as indefinite (i.e., new) when the addressees could infer them from neither actions nor pictures. These addressee-related differences were smaller than those associated with typicality but were nevertheless reliable when the speakers told stories to addressees who had not heard them before.

We see three possible explanations for the discrepancy between Brown and Dell's (1987) findings and ours. Most important, audience design in spontaneous speaking may differ when addressees are confederates. In Brown and Dell's experiment, the two addressees had few if any actual needs; they apparently heard the stories 40 times each, so on most trials they knew the stories far better than the storyteller did. Note that the task of a good confederate is even harder than that of a good actor; a confederate addressee is supposed to provide convincing and consistent feedback across speakers (after all, the main reason to use confederates is to reduce variability). Moreover, feedback must be improvised on each occasion in order to seem contingent on speakers' utterances. This can be challenging because, even in simple, constrained situations, utterances by different speakers can vary a great deal (Brennan
\& Clark, 1996). Although experiments using confederate addressees can be carefully staged so that speakers do not catch on, this by no means guarantees that speakers' utterances are not shaped by factors outside of their awareness. In Brown and Dell's experiment, none of the storytellers appeared to suspect that their partner was a confederate; however, it is possible that the partner's feedback either was simply uninformative or else informed the storytellers that the partner understood the story all too well. In the latter case, such feedback could be as subtle as an acknowledgment spoken just a bit too quickly; for instance, people can reliably judge another's feeling of knowing from how rapidly a response follows a question (Brennan \& Williams, 1995). The point is that, in an investigation of how speakers adjust to addressees, it can be risky to use confederate addressees.

Brown and Dell's (1987) conclusions were also based on a null finding; they may not have had adequate power to detect any small but reliable effects of addressee knowledge. Finally, it is worth noting that although they found no interaction between typicality and addressee, their main effect of addressee did approach significance ( $p=$ .09 ); that is, speakers were marginally less likely to explicitly mention any instrument when the addressee had a picture than when he or she had no picture. This could represent a coarse form of audience design.

Our findings demonstrate that utterance planning does not happen in isolation from the needs of addressees but that speakers can adapt their plans, at least when their addressees' needs are real and they can monitor these needs via visual copresence. However, because conversation is opportunistic and speakers begin speaking before they have finished planning, we do not expect speakers to $a l$ ways adapt to addressees (recall that the effect of addressee knowledge was smaller than that of typicality). In fact, a speech production system that tried for perfect audience design would not be optimal, because addressees can take such an active role in establishing reference and providing evidence about what they understand (Brennan, 1990; Clark \& Brennan, 1991). It would make sense, then, for speakers to sometimes risk relying on this help, rather than to delay speaking in order to plan ideal utterances.

Moreover, we do not claim that speakers adapt to addressees only to the extent that they did in this storytelling task. In our experiment, although visual copresence mattered, the type of visual copresence (whether the partners viewed the same picture or copies of it) did not. However, with a different task, one with steps and dependencies to

Table 3

Percentages of Indefinite References (e.g., Using a, some) in First Mention of Typical and Atypical Instruments in the Three Copresence Conditions

\begin{tabular}{lcc}
\hline \multicolumn{1}{c}{ Copresence Condition } & Typical & Atypical \\
\hline No visual copresence & 19.7 & 30.5 \\
Separate display copresence & 19.4 & 22.3 \\
Full copresence & 21.3 & 25.0 \\
\hline
\end{tabular}


encourage coordination at a finer grain (such as referential communication, giving and following instructions, etc.), differences in the ability to monitor a partner's attention could lead to differences in audience design. Likewise, a task treating utterances as one-shot presentations detached from any joint activity might result in less audience design (for a discussion, see Ferreira \& Dell, 2000).

The question remains of exactly how speakers come to achieve addressee-specific syntactic adjustments. When two partners' knowledge does not coincide (as when only one has a picture) and when such a difference or need is salient enough, this information can influence early syntactic choices. Clearly, monitoring and repair play important roles as well; constituents are monitored for appropriateness either before or after articulation (Levelt, 1989). If constituents are found deficient after articulation begins, adjustments can be made in subsequent clauses. If deficiencies are found before articulation, constituents can be delayed for replanning (covert repair). Our method, adapted from Brown and Dell's (1987), does not distinguish between whether speakers packaged needed information early in the main verb clause by considering addressees' needs from the earliest moments or whether they did so by delaying articulation (there was no way to identify the precise starting moment of planning while the speaker studied the story, nor was there time pressure, since we wished to examine natural speaking). Nevertheless, either possibility constitutes audience design. What we conclude, then, is that when addressees have actual needs, speakers can respond by packaging the needed information early in utterances.

\section{REFERENCES}

Bard, E. G., Anderson, A. H., Sotillo, C., Aylett, M., DohertySneddon, G., \& Newlands, A. (2000). Controlling the intelligibility of referring expressions in dialogue. Journal of Memory \& Language, 42, 1-22.

Bavelas, J. B., Coates, L., \& Johnson, T. (2000). Listeners as conarrators. Journal of Personality \& Social Psychology, 79, 941-952.

Bock, J. K. (1986). Meaning, sound, and syntax: Lexical priming in sentence production. Journal of Experimental Psychology: Learning, Memory, \& Cognition, 12, 575-586.

Bortfeld, H., \& Brennan, S. E. (1997). Use and acquisition of idiomatic expressions in referring by native and non-native speakers. Discourse Processes, 23, 119-147.

BrENNAN, S. E. (1990). Seeking and providing evidence for mutual understanding. Unpublished doctoral dissertation, Stanford University.

Brennan, S. E., \& Clark, H. H. (1996). Conceptual pacts and lexical choice in conversation. Journal of Experimental Psychology: Learning, Memory, \& Cognition, 11, 1482-1493.

Brennan, S. E., \& Williams, M. (1995). The feeling of another's knowing: Prosody and filled pauses as cues to listeners about the metacognitive states of speakers. Journal of Memory \& Language, 34, 383398.

Brown, P., \& Dell, G. S. (1987). Adapting production to comprehension: The explicit mention of instruments. Cognitive Psychology, 19, 441-472.

Clark, H. H., \& Brennan, S. E. (1991). Grounding in communication. In L. B. Resnick, J. Levine, \& S. D. Teasley (Eds.), Perspectives on socially shared cognition (pp. 127-149). Washington, DC: American Psychological Association.

Clark, H. H., \& Marshall, C. R. (1981). Definite reference and mutual knowledge. In A. H. Joshi, B. Webber, \& I. A. Sag (Eds.), Ele- ments of discourse understanding (pp. 10-63). Cambridge: Cambridge University Press.

Dell, G. S., \& BRown, P. M. (1991). Mechanisms for listener-adaptation in language production: Limiting the role of the "model of the listener." In D. Napoli \& J. Kegl (Eds.), Bridges between psychology and linguistics (pp. 105-129). San Diego: Academic Press.

Fernald, A., \& Simon, T. (1984). Expanded intonation contours in mothers' speech to newborns. Developmental Psychology, 20, 104-113.

Ferreira, V. S., \& Dell, G. S. (2000). The effect of ambiguity and lexical availability on syntactic and lexical production. Cognitive Psychology, 40, 296-340.

Fowler, C., \& Housum, J. (1987). Talkers' signalling of 'new' and 'old' words produced in various communicative contexts. Language \& Speech, 28, 47-56.

Fussell, S. R. \& Krauss, R. M. (1991). Accuracy and bias in estimates of others' knowledge. European Journal of Social Psychology, 21, 445-454.

FusSEll, S. R., \& KRauss, R. M. (1992). Coordination of knowledge in communication: Effects of speakers' assumptions about what others know. Journal of Personality \& Social Psychology, 62, 378-391.

Garrod, S., \& ANDERson, A. (1987). Saying what you mean in dialog: A study in conceptual and semantic co-ordination.Cognition, 27, 181218.

Horton, W. S., \& Keysar, B. (1996). When do speakers take into account common ground? Cognition, 59, 91-117.

IsAaCs, E., \& Clark, H. H. (1987). Reference in conversation between experts and novices. Journal of Experimental Psychology: General, 116, 26-37.

Keysar, B., Barr, D. J., Balin, J. A., \& Brauner, J. S. (2000). Taking perspective in conversation: The role of mutual knowledge in comprehension. Psychological Science, 11, 32-37.

Keysar, B., Barr, D. J., \& Horton, W. S. (1998). The egocentric basis of language use: Insights from a processing approach. Current Directions in Psychological Science, 4, 46-50.

Keysar, B., \& Horton, W. S. (1998). Speaking with common ground: From principles to processes in pragmatics. A reply to Polichak and Gerrig. Cognition, 66, 191-198.

Krauss, R. M., \& Weinheimer, S. (1966). Concurrent feedback, confirmation, and the encoding of referents in verbal communication. Journal of Personality \& Social Psychology, 43, 343-346.

Levelt, W. J. M. (1989). Speaking. Cambridge, MA: MIT Press.

Levelt, W. J. M., \& Kelter, S. (1982). Surface form and memory in question answering. Cognitive Psychology, 14, 78-106.

Lieberman, P. (1963). Some effects of semantic and grammatical context on the production and perception of speech. Language \& Speech, 6, 172-187.

Nickerson, R. S., Baddeley, A., \& Freeman, B. (1987). Are people's estimates of what other people know influenced by what they themselves know? Acta Psychologica, 64, 245-259.

Pasupathi, M., Stallworth, L. M., \& Murdoch, K. (1998). How what we tell becomes what we know: Listener effects on speakers' long-term memory for events. Discourse Processes, 26, 1-25.

Polichak, J. W., \& Gerrig, R. J. (1998). Common ground and everyday language use: Comments on Horton and Keysar (1996). Cognition, 66, 183-189.

RaAijmakers, J. G. W., Schrijnemakers, J. M. C., \& Gremmen, F. (1999). How to deal with "the language-as-fixed-effect fallacy": Common misconceptions and alternative solutions. Journal of Memory \& Language, 41, 416-426.

Russell, A. W., \& Schober, M. F. (1999). How beliefs about a partner's goals affect referring in goal-discrepant conversations. Discourse Processes, 27, 1-33.

SAmuel, S. G., \& Troicki, M. (1998). Articulation quality is inversely related to redundancy when children or adults have verbal control. Journal of Memory \& Language, 39, 175-194.

Schober, M. F. (1998). How partners with high and low spatial ability choose perspectives in conversation. Abstracts of the Psychonomic Society, 3, 39 .

Schober, M. F., \& Clark, H. H. (1989). Understanding by addressees and overhearers. Cognitive Psychology, 21, 211-232.

Shatz, M., \& Gelman, R. (1973). The development of communication 
skills: Modifications in the speech of young children as a function of listener. Monographs of the Society for Research in Child Development, 38, 1-37.

WiLKes-GiBBS, D. (1986). Collaborative processes of language use in conversation. Unpublished doctoral dissertation, Stanford University.

\section{NOTES}

1. Such feedback can include backchannels, eye contact, facial expression, gestures, pointing, eye gaze, and other displays of focus of attention.
2. Actually, few participants gestured toward the display; the videotapes were used only to confirm that the participants had followed instructions and had put the text away before retelling the stories.

3. Following the rationale of Raaijmakers, Schrijnemakers, and Gremmen (1999), we do not report $F 2$ of $\operatorname{Min} F^{\prime}$, because our design balances both typicality and copresence within items.

(Manuscript received June 29, 2001; accepted for publication October 15, 2001.) 